\title{
Tipología de vídeos en el periodismo digital español: análisis cualitativo de cinco cibermedios ${ }^{1}$
}

\section{Typology of videos in Spanish online Journalism: A qualitative analysis of five Cybermedia}

\author{
Javier Mayoral Sánchez. Universidad Complutense de Madrid \\ Concha Edo Bolós. Universidad Complutense de Madrid
}

Recibido: 14-II-2014 - Aceptado: 26-IX-2014

Resumen:

El objetivo fundamental de este trabajo es analizar cualitativamente la producción audiovisual de cinco cibermedios españoles: elmundo.es, elpais.com, abc.es, elconfidencial.com y lavanguardia.com. Se pretende establecer una tipología de los vídeos publicados por estos medios para plantear similitudes y diferencias respecto a la producción audiovisual de la televisión clásica. A través de dos trabajos de campo (noviembre de 2010 y marzo de 2014), se constata que la creciente aportación de las agencias de noticias mantiene la conexión - por contenidos, estructuras y estilos- con el periodismo televisivo, mientras que el resto de producción ajena suele generar piezas muy alejadas de los cánones periodísticos audiovisuales. Especial atención merece la producción propia, que constituye un interesante banco de experimentación e innovación en los cibermedios analizados.

Palabras clave:

Prensa digital, cibermedios, multimedia, lenguaje audiovisual, vídeo.

Abstract:

The principal aim of this paper is to analyze qualitatively the audiovisual production of five Spanish digital newspapers: elmundo.es, elpais.com, abc.es, elconfidencial.com y lavanguardia.com. We intend to establish similarities and differences in the audiovisual production of the classic television. Through two fieldworks (November 2010 and March 2014), it is found that the increasing contribution of news agencies maintains-for content, structures and styles- the connection with broadcast journalism, while the outside production usually generates videos very different from the usual videos in broadcast journalism. Special attention should own production, which is an interesting source of experimentation and innovation for online media analyzed.

Key words:

Digital journalism; cybermedia; multimedia journalism; audiovisual language; video.

1 Este artículo se enmarca en el proyecto coordinado Supervivencia del periodismo en la era postdigital. Producción de contenidos en medios emergentes, consecuencias de la participación ciudadana y evolución de las audiencias, financiado por el Ministerio de Ciencia e Innovación (desde el 1 de enero de 2012 hasta el 31 de diciembre de 2014). Los subproyectos, con referencia CSO2011-29510-C03-01 y CSO2011-29510-C03-02, están dirigidos por Concepción Edo Bolós (directora) y Elvira García de Torres. 


\section{Introducción}

Las características fundamentales del lenguaje periodístico de los cibermedios han sido analizadas en multitud de estudios durante los últimos años (Murray, 1999; Nielsen, 2000; Díaz Noci, 2001; Deuze, 2001 y 2004; Manovich, 2005; Salaverría, 2005; Canavilhas, 2007; Masip, 2010, entre otros). De las peculiaridades señaladas por estos y otros autores, cabe destacar al menos cuatro: hipertextualidad, interactividad, actualización constante y multimedialidad. El último rasgo citado resulta de especial interés para la información periodística online por cuanto une "las tradiciones impresas de la narrativa lineal con las capacidades interactivas y multimedia de la informática” (Boczkowski, 2004: 21).

El proceso hacia el lenguaje periodístico hipermedia se encuentra, desde hace unos años, en plena ebullición. En lo referente a la multimedialidad, por fin se han superado ciertas dificultades (tecnológicas, periodísticas, sociales) que venían lastrando su desarrollo durante los primeros años de este siglo. Se suelen considerar tres motivos fundamentales para explicar el desarrollo del vídeo en internet: los nuevos sistemas de compresión de datos, que permiten disminuir el peso de los archivos sin perder excesiva calidad de imagen, la progresiva generalización de las conexiones de banda ancha y el abaratamiento de los costes de las tecnologías digitales (López, 2008).

La tecnología influye decisivamente en la renovación de los lenguajes de la comunicación, puesto que proporciona una infraestructura más versátil, facilita la fluidez de relaciones entre los distintos actores o simplemente permite que se una lo que antes estaba disperso (Negredo, 2013: 122). No obstante, las previsiones para los próximos años recuerdan que las limitaciones de hardware nunca desaparecen: se van de un área para volver a otras (Manovich, 2005: 392). Precisamente uno de los rasgos del nuevo videoperiodismo (Bock, 2012; Lancaster, 2012; Marshall, 2012) es su capacidad para desenvolverse en diferentes entornos de consumo de información. De ahí que el fenómeno multipantalla se considere ahora esencial para estos nuevos medios digitales.

Un estudio de la empresa Alcatel-Lucent ${ }^{2}$ prevé que se duplicará cada año, hasta 2020, el tiempo dedicado por cada usuario de internet a ver vídeos, lo cual obligará a apurar las posibilidades de la actual banda ancha. Quizá la irrupción de YouTube a partir de 2005 haya servido de catalizador. Según datos de la empresa de medición Comscore ${ }^{3}$, el 80\% de los internautas estadounidenses visita este canal de vídeos de Google. Un reciente análisis de YouTube (Peer y Ksiazek, 2011: 45-63) concluye que la mayor parte de los vídeos informativos siguen las pautas tradicionales de producción, pero no sucede lo mismo, por ejemplo, respecto a las fuentes o a la imparcialidad. Y, curiosamente, cuando son reutilizados desde plataformas saltándose los estándares de calidad, aumentan las visitas, lo que puede tener implicaciones en el futuro del

Véase http://www.inversorlatam.com/366437-Internet-el-consumo-de-video-se-duplicara-cada-ano.note.aspx [consultado el 12 de noviembre de 2013].

3 Pueden verse los resultados de este estudio en la página web http://www.comscore.com/Insights/Press_Releases/2011/6/comScore_Releases_May_2011_US_Online_Video_Rankings [consultada el 7 de septiembre de 2013]. 
periodismo. En este sentido resulta muy pertinente la advertencia de Erdal (2009) sobre la reutilización de noticias en los distintos medios.

Desde un punto de vista más amplio, merece la pena considerar estos productos audiovisuales de los cibermedios en relación con la tradición periodística inmediata. Es decir: la tradición audiovisual que ha proporcionado durante más de medio siglo la televisión clásica (véanse, entre otros, García Jiménez, 1993; Oliva y Sitjà, 1992; Vale, 1996; Prósper y López, 1998; Gordillo, 1999; Selinger, 2008; Canet y Prósper, 2009; Mas Manchón, 2011). Esta última miró a la red primero con recelo, y luego con un evidente sentido de la oportunidad que ha propiciado la progresiva convergencia entre soportes (Mayoral et al., 2008: 54). La realidad es que ahora las diferentes audiencias quieren noticias e información en distintos momentos y desde diferentes dispositivos. Ya no son imprescindibles la prensa y la televisión tradicionales (Picard, 2013). Desde luego, y a pesar de esa creciente convergencia tecnológica, admite ya pocas dudas que el periodismo audiovisual online $e^{4}$ no equivale a una simple "televisión en la web" (Bradshaw y Rohumaa, 2011:106), puesto que los vídeos que difunden los medios digitales se integran en relatos con características propias.

Una parte de la atención de los investigadores, durante los dos últimos decenios, se ha centrado justamente en el análisis de las tareas de producción y en cuestiones relativas al avance tecnológico. Desde los primeros estudios (Cottle y Asthon, 1999) hasta los más recientes (Boczkowski, 2004; William y Franklin, 2007; Thurman y Lupton, 2009; Bock, 2012; Lancaster, 2012), esta corriente ha empleado habitualmente un método etnográfico. Su objetivo fundamental consistía en describir las tareas que realizan los periodistas y el modo en que les afectan los cambios tecnológicos. También se han examinado los diferentes tipos de redacción o empresas periodísticas, las dinámicas laborales que en ellas se generan, los elementos que condicionan la rentabilidad del negocio y, en los últimos tiempos con particular intensidad, cuestiones relativas a la convergencia periodística (véanse, verbigracia, Micó, Masip y Barbosa, 2009; Masip, 2010).

Otro grupo de trabajos ha centrado su interés en la recepción de los mensajes (Berry, 1999; Sundar, 2000), partiendo de la idea de que no basta con una simple yuxtaposición de contenidos (Deuze, 2001; Canavilhas, 2007; Micó y Masip, 2008). Más complejo resulta identificar la mejor forma de coordinar contenidos audiovisuales y textos. Se acostumbra a indicar en esta clase de estudios que sonidos e imágenes logran que el mensaje periodístico gane capacidad de atracción, pues el lector se convierte en espectador de primera línea al tener la sensación de estar inmerso en decurso de los hechos (Zamarra López, 2010). No obstante, esto no significa necesariamente que se consiga una mayor comprensión de los contenidos (Canavilhas, 2007: 62).

4 Se prefieren en este trabajo, sin excluir otras posibles denominaciones, las expresiones "periodismo audiovisual en internet", "vídeos periodísticos online" o "vídeos de cibermedios". En cualquier caso, el término "vídeo" se emplea en estos contextos en un sentido general que no debe confundirse con un formato concreto (el "vídeo" entendido como VTR). Se intenta evitar el adjetivo "informativo" porque excluye los géneros de opinión. 
Como explican Masip et al. (2010), una tercera corriente de investigadores (Neuberger et al., 1998; Schultz, 1999; Greer y Mensing, 2006; Russial, 2009) ha optado por realizar análisis de contenido para cuantificar el grado de implantación de los vídeos en los cibermedios. Los trabajos publicados durante los últimos años (Micó y Masip, 2008; Guallar, 2008) subrayan que el peso de lo audiovisual ha crecido en los medios digitales. Es cierto que los vídeos han estado presentes en el periodismo online casi desde su nacimiento (Neuberger et al., 1998; Shultz, 1999). Y también cabe mantener que se trata de un recurso aún no explotado al límite de sus posibilidades (Russial, 2009). Sin embargo, lo que cada vez parece más claro es que las piezas audiovisuales han ganado un notable protagonismo en los cibermedios (Greer y Mensing, 2006; Guallar, Rovira y Ruiz, 2010).

La mayoría de diarios digitales españoles, tras un lento desarrollo, incluye de manera asidua y sistemática vídeos junto a los textos tradicionales (Micó y Masip, 2008; Marrero, 2008; Masip y Micó, 2010; Masip, Micó y Meso, 2012; Cassany et al., 2013). Pero conviene insistir en el matiz: de un modo lento, a veces incluso experimental. De ahí que convenga estudiar con detalle cómo son estas piezas, a qué modelos responden, qué patrones estructurales y narrativos reproducen, qué propuestas originales se atisban en la producción audiovisual de los cibermedios. Y todo ello, desde una perspectiva estrictamente audiovisual, sin entrar a considerar aspectos que abocan a un análisis, más amplio y ambicioso, de la narrativa multimedia.

\section{Objetivos y metodología}

El objetivo fundamental de esta investigación es establecer una tipología de los vídeos publicados en la página principal o portada de cinco cibermedios españoles: elmundo.es, elpais.com, abc.es, elconfidencial.com y lavanguardia.com ${ }^{5}$. No se trata de un mero afán taxonómico, sino de determinar qué clase de piezas audiovisuales ofrecen los diarios digitales que conforman la muestra analizada. Tal planteamiento obliga a centrar la atención en el discurso audiovisual propiamente dicho (en el vídeo en sí), dejando para otra clase de investigaciones el análisis profundo sobre la relación entre los textos del cibermedio y las piezas audiovisuales.

En el primer trabajo de campo la muestra correspondió a los vídeos difundidos por esos cinco medios entre el 2 y el 15 de noviembre de 2010. La segunda parte del trabajo ${ }^{6}$ se desarrolló entre el 18 y el 31 de marzo de 2014. La muestra total se com-

5 Estas son, según los datos de la empresa Comscore, las cinco cabeceras con mayor número de páginas vistas en 2012. Se ha elegido esa fecha porque se sitúa justo entre los dos trabajos de campo realizados: 2010 y 2014. Se opta por el criterio de "número de páginas vistas" porque introduce precisión respecto al dato -más vago y con frecuencia equívoco- de "usuarios únicos". Comscore es la empresa de medición de audiencias recomendada, desde finales de 2011, por la IAB (Interactive Advertising Bureau), asociación que representa al sector de publicidad en los medios digitales en España, y la AIMC (Asociación para la Investigación de Medios de Comunicación). También son aceptados en el sector los datos que publica OJD, aunque en este caso se registran navegadores (a través de las cookies de las páginas web), mientras que Comscore emplea además una encuesta entre usuarios.

6 Este estudio forma parte de una investigación más amplia cuyo principal objetivo es analizar la evolución, entre 2010 y 2015, de la pro- 
pone de 1006 vídeos (388 en 2010 y 618 en 2014). Como es lógico, se ha evitado introducir cambios metodológicos que impidieran comparar los datos obtenidos en los dos trabajos de campo. Durante las cuatro semanas analizadas se realizó un solo registro diario ${ }^{7}$. En ambos casos se encargó de registrar los datos un solo codificador. Para completar de modo sistemático el estudio de cada pieza audiovisual se empleó una ficha de análisis que se reproduce en el Cuadro 1. Como se puede comprobar, esta ficha incluye algunas otras cuestiones no relacionadas con la tipología de vídeos que aquí se examina ${ }^{8}$.

En esta investigación se ha optado por analizar la producción audiovisual de los cinco cibermedios citados desde una perspectiva cualitativa que, no obstante, toma como punto de partida las cuantificaciones realizadas durante el registro diario de la muestra. Por tanto, este estudio cristaliza en observaciones sobre modos de producción audiovisual -es decir, en consideraciones de carácter cualitativo-, pero se fundamenta en datos obtenidos mediante técnicas cuantitativas. El propósito fundamental de la investigación, según se anotó más arriba, es establecer una tipología de los vídeos elaborados por los medios digitales analizados. Para ello se estudiarán los géneros empleados, los formatos utilizados, las estructuras narrativas de las piezas, el origen de los materiales publicados y el grado de elaboración de los vídeos.

Resulta fundamental para este estudio el análisis comparativo de los datos recabados en los dos trabajos de campo. Esta investigación, frente a otras propuestas de naturaleza similar, se propone reflexionar sobre la evolución de la producción audiovisual en las cinco cabeceras consideradas. Ese carácter diacrónico permitirá sostener, con todas las salvedades necesarias en cada caso, algunos pronósticos sobre el futuro inmediato de las producciones audiovisuales en los cinco cibermedios que aquí se estudian. Cada una de esas producciones, además, presenta características propias que se irán analizando de forma individual.

ducción audiovisual, de los procedimientos narrativos y de la tipología de vídeos en los cinco cibermedios citados. Un primer esbozo de este proyecto se formuló en el III Congreso de Ciberperiodismo y Web 2.0, celebrado en Bilbao entre el 9 y el 11 de noviembre de 2011. La comunicación presentada en dicho congreso se tituló "El incipiente desarrollo del ciberperiodismo audiovisual. Análisis de ocho cibermedios españoles". Para la determinación de las muestras se buscaron dos tramos temporales en los que, en principio, hubiera una actividad periodística normal (se excluyeron los meses de verano y algunos meses en los que hubiera periodos vacacionales, como enero o diciembre): mediante azar no probabilista se estableció que los trabajos de campo de 2010 y 2011 se realizaran en noviembre, mientras que los de 2014 y 2015 se hicieran en marzo.

7 Los días impares se optó por un horario de mañana (a partir de las 11:00 horas). Los días pares se prefirió el horario de tarde (a partir de las 20:00 horas). En el trabajo de campo de 2011 se realizaron, en primera instancia, dos registros diarios: el primero de ellos comenzaba a las 11:00 horas; el segundo, a las 21:00 horas. En 2014 se renunció a ese doble registro porque pudo comprobarse que la presencia de los vídeos en las portadas analizadas superaba con creces las doce horas, por lo que el doble registro solo servía para duplicar los datos de vídeos ya registrados. De ahí que en este estudio se prescinda finalmente del segundo registro (tanto en la muestra de 2014 como en la de 2011, como es lógico)

8 Véase la nota $n^{\circ} 6$. 
Cuadro 1. Ficha de análisis empleada para el conjunto de la investigación

\begin{tabular}{|c|c|}
\hline DÍA: & \\
\hline MEDIO: & \\
\hline VÍDEO & \\
\hline GÉNERO & $\begin{array}{l}\text { NOTICIA, CRÓNICA, ENTREVISTA, REPORTAJE, FRAGMENTO PROGRAMA, } \\
\text { OTROS }\end{array}$ \\
\hline FORMATO & VTR, COLAS, TOTAL/TOTALES, COLAS + TOTAL, CLIP, OTROS \\
\hline UBICACIÓN & UBI 1, UBI 2, UBI 3 \\
\hline DURACIÓN & \\
\hline AUTORÍA / ORIGEN & PROPIA, AGENCIAS, AJENA \\
\hline TEMÁTICA GENERAL & $\begin{array}{l}\text { INTERNACIONAL, NACIONAL, ECONOMÍA, SOCIEDAD, MÚSICA, CULTURA, } \\
\text { CINE, FÚTBOL, OTROS. }\end{array}$ \\
\hline TEMA CONCRETO & \\
\hline TIPO DE ESTRUCTURA & $\begin{array}{l}\text { P. INVERTIDA, P. DISEMINADA, NARRATIVA, EXPOSITIVA, ARGUMENTATIVA, } \\
\text { CRONOLÓGICA, OTRAS }\end{array}$ \\
\hline Comienzo de texto & [Para análisis cualitativo] \\
\hline Final de texto & [Para análisis cualitativo] \\
\hline Elementos internos & [Para análisis cualitativo: función estructural] \\
\hline TIPO DE EDICIÓN & IN-OUT, ELEMENTAL, COMPLEJA GRADO 1, COMPLEJA GRADO 2 \\
\hline PRESENTACIÓN DEL AUTOR & EN PANTALLA, CON RÓTULO, OTRAS. \\
\hline MODO DE NARRACIÓN & LOCUCIÓN, CON TOTALES, SIN LOCUCIÓN Y SIN TOTALES, OTRAS \\
\hline PLANOS & \\
\hline RÓTULOS & \\
\hline Número de rótulos & \\
\hline Tipos de rótulos & $\begin{array}{l}\text { TEMÁTICOS, IDENTIFICATIVOS, TEMPORALES, SUBTÍTULOS, INFORMA, } \\
\text { OTROS. }\end{array}$ \\
\hline COORDINACIÓN TEXTO IMAGEN & \\
\hline Tipos & JERARQUÍA PARCIAL O TOTAL, COMPLEMENTARIEDAD PARCIAL O TOTAL \\
\hline Observaciones & \\
\hline TOTALES & \\
\hline Recursos de interés & \\
\hline Otros & \\
\hline
\end{tabular}

Fuente: Elaboración propia 
La hipótesis de la que se parte en esta investigación puede resumirse así: los vídeos de los cibermedios analizados constituyen un conjunto multiforme y heterogéneo, pues en realidad responden a modelos audiovisuales muy diversos, con rasgos y planteamientos formales difícilmente comparables. Habrá que confirmar o desmentir si también a este respecto los cibermedios alcanzan un alto grado de hibridación al alternar propuestas de nítido perfil periodístico (relacionadas con el canon establecido durante decenios por la televisión clásica) con piezas sin ningún patrón estructural, conceptual o estilístico que recuerde siquiera al periodismo audiovisual.

Como complemento de esa hipótesis principal, esta investigación se propone corroborar o rechazar esta otra: los cibermedios estudiados están conformando, gracias fundamentalmente a la producción propia, una narrativa audiovisual cada vez más alejada de los moldes televisivos. Se pretende, por tanto, dilucidar en este trabajo si se está constituyendo una narrativa audiovisual -al margen de consideraciones relativas al concepto de multimedialidad-adaptada al nuevo soporte digital. De existir, este nuevo modelo se encontraría en una fase aún embrionaria. En primer lugar, porque parece convivir con otras tendencias de signo opuesto. Y, en segundo lugar, porque la producción propia de los cibermedios no ha dado señales de avanzar durante los últimos años con fuerza, sino más bien muy tímidamente (Micó y Masip, 2008; Masip, Micó y Meso, 2012).

\section{Resultados}

Antes de establecer los tipos de vídeos hallados en este estudio, conviene aportar una serie de datos sobre el conjunto de las muestras analizadas. La producción audiovisual ${ }^{9}$ de los cinco cibermedios considerados crece un 59,28\% entre los trabajos de campo de 2010 y 2014. De las 388 piezas registradas en la primera muestra se pasa a 618 en la segunda. Según puede observarse en el Cuadro 2, el único medio en el que decrece la difusión de vídeos es elpais.com, donde se registra un descenso del 12,7\% (18 piezas menos en 2014). Lavanguardia.com y elmundo.es experimentan subidas considerables (44,2\% y 71,7\%, respectivamente), pero todavía muy alejadas de los ascensos en la producción audiovisual de abc.es y elconfidencial.com. En estos dos cibermedios la publicación de vídeos en portada se triplica entre 2010 y 2014.

9 Como se explicó más arriba, se ha recurrido a un solo registro diario. Los datos correspondientes a cada vídeo (véase el Cuadro 1) se han contabilizado tantas veces como aparece dicho vídeo en los registros efectuados. Si un vídeo se difunde dos veces en la misma portada, se computan dos piezas idénticas (salvo en lo relativo a la ubicación, por supuesto). Si esa pieza permanece en portada al día siguiente, vuelve a incluirse de nuevo en las fichas de registro. 
Cuadro 2. Número de vídeos publicados en la página principal de los cinco cibermedios

\begin{tabular}{|c|c|c|c|c|c|}
\hline & abc.es & elconfidencial.com & elmundo.es & elpais.com & lavanguardia.com \\
\hline 2010 & 47 & 24 & 46 & 142 & 129 \\
\hline 2014 & 156 & 73 & 79 & 124 & 186 \\
& $(+231,9 \%)$ & $(+204,2 \%)$ & $(+71,7 \%)$ & $(-12,7 \%)$ & $(+44,2 \%)$ \\
\hline
\end{tabular}

Fuente: Elaboración propia

El Cuadro 3 permite ver que, entre los géneros periodísticos clásicos, la noticia sigue siendo la opción preferida. En términos comparativos incluso gana protagonismo, puesto que respecto a 2010 se advierte un incremento de casi 14 puntos porcentuales. Si en 2010 las noticias suponían el 36,86\% del conjunto de la muestra, en 2014 el registro informativo puro alcanza el 50,16\% del total de vídeos registrados. La opinión, en cambio, sufre un notable retroceso: pasa de suponer el 7,22\% de la muestra de 2010 a un 3,07\% en 2014. Más brusca aún es la caída de la crónica (del 11,60\% al 3,37\%). En el resto de géneros informativos e interpretativos se constata cierta estabilidad. La entrevista y el reportaje se encuentran a gran distancia de la noticia. El reportaje casi dobla su producción en términos absolutos, pero en términos relativos -teniendo en cuenta el aumento total de la muestra en 2014- sube poco más de un punto (desde el 11,08\% en 2010 hasta el 12,27\% en 2014). La entrevista, en cambio, pierde algo de presencia (pasa de un 4,90\% a un 4,37\%).

Cuadro 3. Géneros periodísticos de las piezas estudiadas

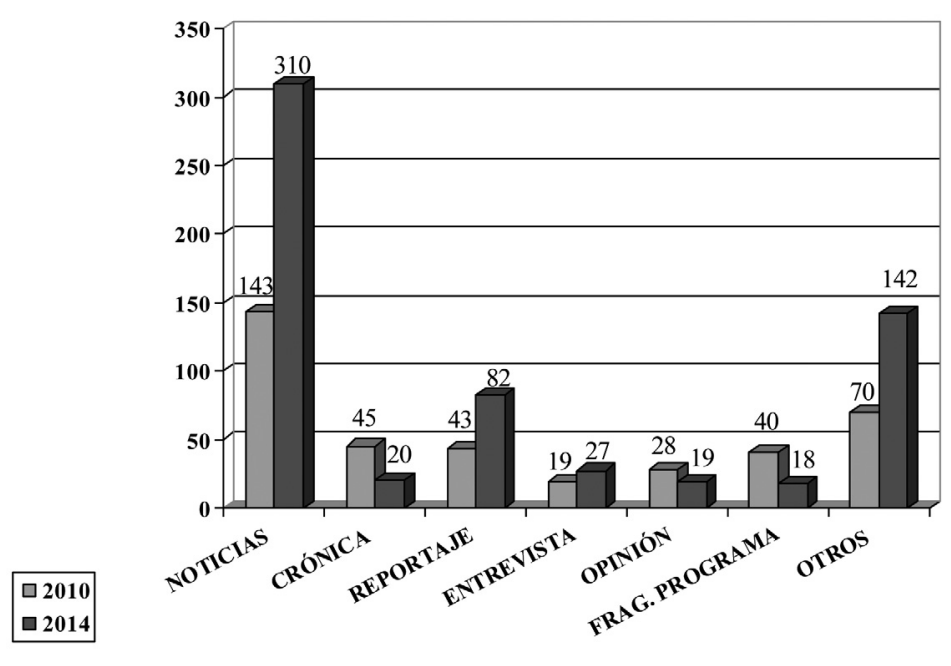

Fuente: Elaboración propia 
Las dos últimas categorías del Cuadro 3 pretenden registrar piezas que escapan a las consideraciones y criterios clásicos de la Teoría de los Géneros. En 2010 se observó que una buena parte de esos vídeos inclasificables procedía de programas de televisión. Los fragmentos de programas televisuales (e incluso programas completos) suponían el 10,31\% de la muestra. En 2014 esa tendencia se ha frenado notablemente (2,91\%). Sin embargo, la categoría de “Otros”, que ya en 2010 superaba a la suma de reportajes y entrevistas, en 2014 equivale casi a la suma de todos los géneros periodísticos, exceptuando la noticia. Estas piezas que no se dejan adscribir a los géneros periodísticos tradicionales han pasado de suponer el 18,04\% del conjunto de vídeos en 2010 a un 22,98\% en 2014. Dicho de otro modo: en el último trabajo de campo esta categoría acoge a una de cada cuatro piezas.

Cuadro 4. Temáticas abordadas en los vídeos de portada de los cinco cibermedios seleccionados

\begin{tabular}{|c|c|c|c|c|c|c|c|}
\hline & Nacional & Internacional & Economía & Sociedad & Cultura & Fútbol & Otros \\
\hline 2010 & 21 & 23 & 7 & 60 & 112 & 59 & 106 \\
\hline 2014 & 81 & 48 & 23 & 182 & 93 & 73 & 118 \\
\hline
\end{tabular}

Fuente: Elaboración propia

También es llamativo el peso de la categoría “Otros” (27,32\% en 2010 y 19,09\% en 2014) en el Cuadro 4, en el que se cuantifican los temas que abordan los vídeos analizados. Los contenidos de "Sociedad” son ya mayoritarios (29,45\%) en 2014. Los incrementos de las categorías de "Nacional” (7,7 puntos porcentuales), "Internacional” (1,84 puntos) y "Economía" (1,92 puntos) vienen a reflejar, como se explicará más adelante, el auge de la producción audiovisual procedente de las agencias de noticias. Los contenidos relacionados con "Cultura" pierden protagonismo, pues pasan del 28,87\% en 2010 a un $15,05 \%$ en 2014. Pudiera sorprender, con todo, la gran cantidad de piezas que acumula esta categoría de "Cultura”. Téngase en cuenta que se incluyen ahí los vídeos relacionados con música y cine ${ }^{10}$ : en total, 88 piezas en 2010 y 74 en 2014.

El Cuadro 5 muestra, en coherencia con lo anterior, una apuesta por formatos (“Clip" y "Otros”) cuantitativamente irrelevantes en la escaleta de los informativos televisuales clásicos. En el último grupo (“Otros”, 26,86\% en 2014) se integran también los falsos directos, que en los cibermedios asumen algunos de los usos y las funciones -personalización o relato asociado a un tiempo y un espacio, por ejemplo- que la televisión clásica asigna al directo. El VTR o vídeo, con locución grabada, pierde presencia (diez puntos porcentuales: del 51,55\% al 41,26\%) en términos relativos. La combinación de colas

10 En las fichas de registro, a diferencia de lo que sucede en el Cuadro 4, se ha distinguido entre "Cine", "Música” y "Cultura” para poder relacionar las temáticas abordadas con el grado de elaboración y la procedencia de los vídeos. En el caso del cine y de la música, el cibermedio se limita con frecuencia a reproducir el tráiler o el videoclip suministrado por productoras o agencias. No suele ocurrir lo mismo con otros contenidos de carácter cultural (teatro o literatura, por ejemplo). En cuanto a la categoría de "Fútbol", se ha utilizado porque resulta mucho más informativa y precisa que otras de carácter genérico (“Deportes”, por ejemplo): ya en la muestra de 2010 se constató que, de cada diez piezas sobre deportes analizadas, nueve se centraban en el fútbol. 
y totales, frecuente en el periodismo televisivo (Oliva y Sitjà, 1992: 155; Cebrián Herreros, 1998: 216; Mayoral et al., 2008: 65), tiene en los ciberdiarios analizados un valor casi testimonial. En 2014 no pasa del 2,10\% en el conjunto de la muestra.

Cuadro 5. Formatos de las piezas audiovisuales analizadas

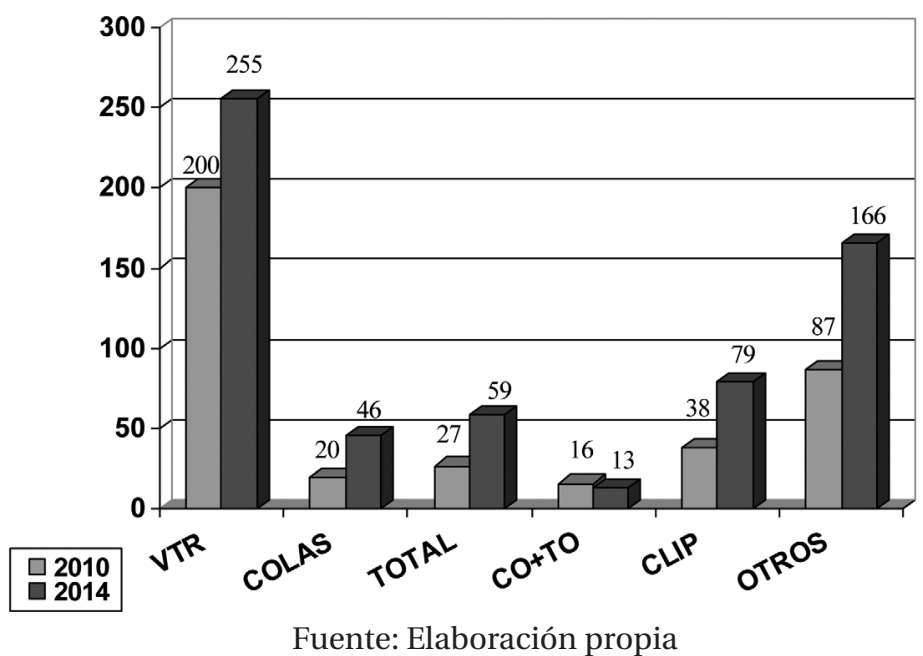

La duración media de las piezas en el estudio de 2010 se situaba en dos minutos y 14 segundos. En 2014 se mantiene en 2 minutos y 20 segundos. La locución tradicional (voz en off) sigue siendo la fórmula más empleada para encauzar la narración, pues se utiliza en el 58,71\% de los VTR registrados en 2011. En 2014 la voz en offaparece en el 51,97\% de los casos. Aumenta, en cambio, la narración que se sustenta en totales (fragmentos de entrevista) y en planos con su propio sonido ambiente. Este procedimiento se utilizó 42 veces en la muestra de 2010 y 82 veces en la de 2014. En ese periodo el uso de totales se duplica con creces: de 453 se pasa a 1046.

\subsection{Materiales sin editar y "semibrutos"}

Para trazar una tipología de vídeos en la muestra analizada puede resultar muy útil un dato sobre el grado de elaboración durante el montaje ${ }^{11}$ : el 41,25\% de las piezas refleja una sencillez extrema. Del total de 1006 vídeos examinados, 415 co-

11 Las categorías empleadas en este trabajo -y reflejadas en el Cuadro 6- son las siguientes: "in-out” (mera reproducción o copia, sin edición alguna del vídeo); "elemental" (hasta siete operaciones de edición); "grado 1" (entre siete y 15 acciones de edición); "grado 2" (más de 15 acciones de edición). En el tipo de edición denominado "elemental” se ha intentado buscar un grado de complejidad equivalente a unas colas televisuales de 25-30 segundos. Con el llamado "grado 1" se pretende establecer una categoría que proponga un nivel de complejidad equivalente a un vídeo de 50-60 segundos. El "grado 2" representa un esfuerzo de edición superior a todos los anteriores.

$40 \mid n^{\circ}$ 19, pp. 31-56 | doxa.comunicación 
rresponden a simples reproducciones ("in-out", en el Cuadro 6) de productos que han sido elaborados en instancias ajenas a los cibermedios considerados. En términos relativos, estos vídeos copiados o reproducidos constituyen el 50,52\% del conjunto de piezas de 2010 y el 35,44\% de la muestra de 2014. En este último trabajo de campo las dos primeras categorías del Cuadro 6 (menos de ocho operaciones de edición) se hallaban en el 55,98\% de los vídeos analizados. El denominado "Grado 1" aparece tan solo en el 13,92\% de las piezas de 2014; el llamado "Grado 2", en el 30,10\%. Los datos de 2010 son aún más nítidos: solo el 34,02\% de las piezas evidencian una tarea de edición de "Grado 1” o "Grado 2".

Cuadro 6. Tipo de edición y complejidad técnica de los vídeos registrados

\begin{tabular}{|c|c|c|c|c|}
\hline & In-out & Elemental & Grado 1 & Grado 2 \\
\hline 2010 & 196 & 60 & 52 & 80 \\
\hline 2014 & 219 & 127 & 86 & 186 \\
\hline
\end{tabular}

Fuente: Elaboración propia

Tan escasa complejidad técnica debe ser relacionada con un alto porcentaje de producción ajena. El Cuadro 7 refleja incluso una dependencia creciente de los cibermedios estudiados respecto a esa producción audiovisual externa. En 2010 la producción ajena alcanzaba al 66,49\% de los vídeos registrados. En 2014 se llegaba a un 68,77\% del conjunto de la muestra analizada. Para intentar clarificar la situación en lo posible, el Cuadro 7 especifica, dentro de la producción ajena, cuántas piezas han sido elaboradas por las agencias de noticias. Las restantes (185 en 2010 y 236 en 2014) conforman un conjunto de vídeos sobre el que conviene detenerse, puesto que constituye el primer tipo de piezas que serán examinadas en este trabajo.

En el caso de un vídeo de producción ajena, el cibermedio analizado se limita a copiar un archivo e insertarlo en su página principal. Incluso en el hipotético caso de que el vídeo reproducido muestre un cierto grado de complejidad y un notable esfuerzo durante el montaje, tal tarea habrá sido realizada por terceros, por personas completamente ajenas a la redacción de la cabecera que se estudia. Esto sucede a menudo con piezas procedentes de algunas cadenas de televisión. En elpais.com, por ejemplo, se aprovechan informaciones elaboradas y ya difundidas en Canal Plus. Ocurre también en las crónicas de fútbol que, procedentes de Gol Televisión, llegan a la portada de elmundo.es. Alguna vez incluso se ha registrado una pieza que había sido grabada y editada por protagonistas de la información que se aborda. El 21 de marzo elmundo.es publicó un VTR de tres minutos y medio -sin locución, pero con totales, ambientes y rótulos- montado por los propios manifestantes de las llamadas "marchas por la dignidad". 
Cuadro 7. Tipo de producción audiovisual en los medios estudiados

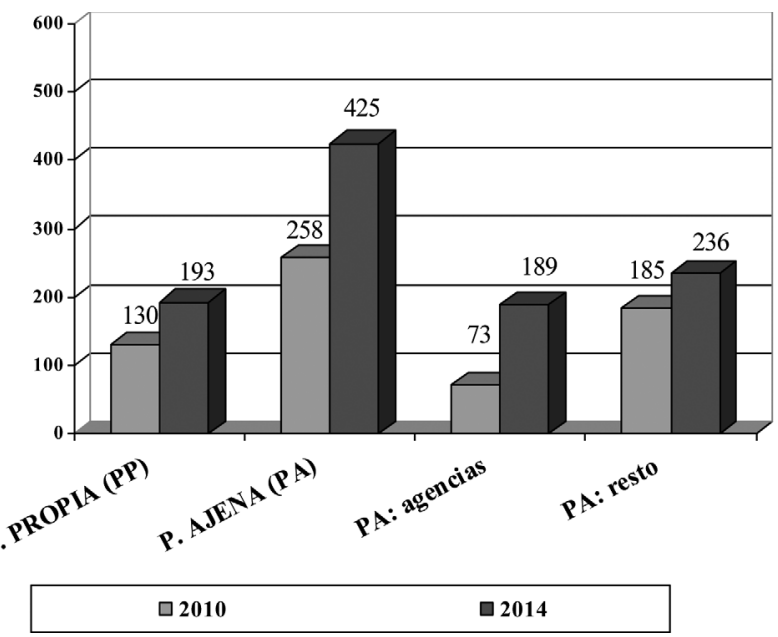

Fuente: Elaboración propia

Esta práctica es consecuencia directa de ciertos acuerdos de colaboración (elpais.com y Canal Plus, por ejemplo, forman parte del mismo grupo empresarial), pero responde también a una tendencia más general que puede ser resumida en los siguientes términos: los medios analizados reproducen, siempre que pueden, toda clase de vídeos, pues parecen considerar que el propio formato es en sí mismo atractivo. Ya se anotó más arriba al comienzo del capítulo anterior que la producción audiovisual de los cinco cibermedios seleccionados había aumentado más de un 59\% entre 2010 y 2014.

Incluso a los diarios que más cuidan la producción propia (lavanguardia.com, en especial) les cuesta renunciar a estos materiales de libre difusión. De hecho, en este medio la producción ajena, descontando las piezas de agencias, se sitúa en un 40,86\%. El tipo de edición denominado "in-out" acapara el 38,17\% de las piezas difundidas en la portada de este medio. El día 26 de marzo de 2014, por ejemplo, lavanguardia.com y abc.es publican en su página principal un vídeo procedente de YouTube: se trata de la caída en un plató de televisión de un torero famoso, Cayetano Rivera Ordóñez. Los dos medios se limitan a reproducir un fragmento de un programa de televisión ("El Hormiguero", del canal Cuatro) que incluye la escena, sin duda impactante, del momento en que el torero cae de unas grúas. Ese mismo día, además de otros dos vídeos de YouTube, lavanguardia.com coloca en portada una pieza procedente de la versión online del Daily Mail (dailymail.co.uk). Se da cuenta en este vídeo de un experimento relativo a la colaboración ciudadana en casos de secuestros de niñas.

En los ejemplos anteriores se constata un trabajo de edición más o menos complejo, pero siempre ajeno por completo a los medios que aquí se estudian. Los cibermedios analizados se limitan a difundir materiales que otros han elaborado. 
Esta práctica, aunque se documenta en toda clase de circunstancias, resulta muy recurrente cuando el vídeo muestra algo emotivo, espectacular, excepcional o simplemente curioso: un sensual baile de la cantante Shakira (lavanguardia.com, 27/03/2014), la primera aparición pública de dos osos polares gemelos en Munich (abc.es, 20/03/2014), dos guardias civiles que ayudan a parir a un tiburón en Fuengirola (elmundo.es, 28/03/2014) o una campaña publicitaria -con locución en danés- para fomentar la natalidad en Dinamarca (elconfidencial.com, 28/03/2014).

Cuadro 8. Producción ajena (sin piezas de agencias) ${ }^{12}$

\begin{tabular}{|c|c|c|c|c|c|}
\hline & abc.es & elconfidencial.com & elmundo.es & elpais.com & lavanguardia.com \\
\hline \multirow{2}{*}{2010} & 16 & 24 & 24 & 94 & 27 \\
& $(34,04 \%)$ & $(100 \%)$ & $(52,17 \%)$ & $(66,20 \%)$ & $(20,93 \%)$ \\
\hline \multirow{2}{*}{2014} & 69 & 55 & 16 & 20 & 76 \\
& $(44,23 \%)$ & $(75,34 \%)$ & $(20,25 \%)$ & $(16,12 \%)$ & $(40,86 \%)$ \\
\hline
\end{tabular}

Fuente: Elaboración propia

De entre los cinco cibermedios seleccionados, como puede deducirse de los datos incluidos en el Cuadro 8, el que más frecuentemente recurre a este tipo de vídeos es elconfidencial.com. Frecuentemente y -cabe añadir- también sistemáticamente, pues cuenta con un espacio, en el tramo inferior de su portada, destinado a publicar día tras día estas piezas de carácter anecdótico que muchas veces se han convertido en vídeos virales. En esta cabecera el 75,34\% de la producción audiovisual de 2014 es de producción ajena (sin contar aquí las noticias de agencias). También el 75,34\% de sus vídeos son meras reproducciones de materiales ajenos. No obstante, se advierte en el trabajo de campo de 2014 un cierto grado de selección de materiales. En 2010 toda la producción audiovisual de elconfidencial.com (24 vídeos, con un total de cinco minutos y 20 segundos) era de producción externa. No se halló entonces en este medio ni un solo trabajo de producción propia o de agencias.

Además de piezas de producción ajena y fragmentos sin editar, cabe incluir en esta categoría una serie de vídeos que pueden ser denominados "semibrutos". En cierto modo son resúmenes de materiales en bruto: un estadio intermedio entre el bruto propiamente dicho (la grabación original del camarógrafo) y las piezas definitivas que culminan un proceso de edición. Es decir, las agencias de noticias o los profesionales del propio medio graban primero y seleccionan después una serie de planos. Lo peculiar de estos "semibrutos" es que la tarea de montaje resulta mínima, primaria, ajena a los procedimientos sintácticos que suelen respetarse en la narrativa audiovisual. Hay pocas operaciones de edición (cortes de planos, con sus correspondientes órdenes de entrada y salida). Y estos planos, por lo general de gran extensión, saltan, pues se infringen -sin voluntad de estilo, claro está- las reglas de continuidad (o raccord).

12 Entre paréntesis se añade el tanto por ciento correspondiente al total de la producción audiovisual de cada medio. 
Esta última variedad de vídeos de producción ajena se hallaba con más facilidad en la muestra de 2010, pero aún se localizan con cierta facilidad en 2014. El día 20 de marzo, por ejemplo, elmundo.es publica en portada una pieza de tres minutos y 29 segundos: el ex torero José Ortega Cano acompaña a su hijo José Fernando al Instituto Hipócrates de Barcelona. Aquí realmente no hay trabajo de edición, pues los tres minutos y medio están ocupados por un único plano. El esfuerzo de selección es mínimo. Otras veces lo que ocurre es que se producen saltos de raccord. El 19 de marzo abc.es difunde un vídeo de casi dos minutos en el que se incluyen once planos (la media es de algo más de diez segundos para cada plano). Se trata de una noticia sobre la muerte de una niña en la localidad de Treviño. Las violaciones de las normas habituales de montaje son continuas. Lo mismo ocurre con un vídeo de cuatro minutos y 45 segundos sobre la muerte del alcalde de Bilbao, Iñaki Azkuna, publicado por elmundo.es el 24 de marzo.

Un último ejemplo de "semibruto" (material de resumen, con edición elemental, sin relato audiovisual en sentido estricto): el 26 de marzo incluye en su portada un material audiovisual de un minuto y 40 segundos relacionado con el vuelo 370 de Malaysa Airlines. Se confecciona un material útil para articular una narración audiovisual, pero ese premontaje no conforma por sí mismo tal narración. Las imágenes se suceden sin gramaticalidad ni estrategia textual aparente. Se emplean dos totales y planos de recursos en orden aleatorio. Poco que ver con el vídeo (VTR) de un minuto y medio que, sobre este mismo tema, elabora la agencia EFE y difunde elmundo.es (19 de marzo). Aquí sí hay edición y selección.

No resulta sencillo caracterizar con nitidez esta primera categoría de vídeos, puesto que se trata de un grupo muy heterogéneo de piezas. Cabe señalar, no obstante, algunos rasgos: duración imprevisible, contenidos anecdóticos o emotivos, mínimo o inexistente trabajo de edición o procedencia dispar (canales especializados en vídeos como YouTube, otros cibermedios, programas de televisión o agencias). Conviene enfatizar una última característica de estos materiales sin editar y “semibrutos": la tendencia a evitar estructuras, estilos, contenidos y formatos típicamente periodísticos.

Este último rasgo -la elusión de arquetipos periodísticos- ayuda a entender por qué son tan altos los porcentajes correspondientes a las categorías de "Otros" en los Cuadros 3, 4 y 5. En buena medida tiene que ver con la ya comentada propensión de los cibermedios a incluir en su portada toda clase curiosidades y anécdotas que pueden llamar la atención de los lectores. Quiere eso decir que estos materiales audiovisuales son apreciados, más que por su valor informativo, por su capacidad para suscitar intriga, para plasmar escenas pintorescas o para mostrar situaciones comprometidas. Se busca (y esto sucede en mayor o menor media en todos los medios analizados) un estímulo que, por irrelevante que resulte, logre captar a la audiencia. Todas estas piezas, además de curiosas o espectaculares, apenas comportan gasto alguno, puesto que el cibermedio se limita a copiar un vídeo o a enlazar con otra página web. 


\subsection{La producción de las agencias}

Uno de los cambios más visibles, al comparar los trabajos de campo de 2010 y 2014, afecta de modo directo a las agencias de noticias. El aumento de su producción resulta incuestionable. En la primera muestra se hallaron 73 vídeos de agencias. En la segunda, 189. Esto supone un incremento del 158,9\%, porcentaje ni por asomo comparable al 25,57\% de crecimiento correspondiente al resto de producción ajena (ni tampoco a la subida del 48,46\% en la producción propia).

Los datos del Cuadro 9 muestran que se trata de una tendencia generalizada. Los cinco cibermedios considerados aumentan la publicación de piezas audiovisuales procedentes de las agencias (sobre todo de EFE y Atlas, y en menor media de Europa Press) en términos absolutos. En términos relativos -considerando el porcentaje que representan los vídeos de agencia dentro de la producción total de cada medio-, solo en abc.es pierden estas piezas algo de protagonismo. Las demás cabeceras aumentan significativamente su dependencia de las agencias. En los casos de elmundo.es y de la vanguardia.com se puede considerar que los vídeos de agencia suben de forma moderada (siete y diez puntos, respectivamente). Más llamativa es la situación de elconfidencial.com. No se halló en este medio ni un solo trabajo de agencia en la muestra de 2010, pero en 2014 se concede a las agencias un 12,33\% de la producción audiovisual. Y más aún destaca la evolución de elpais.com, donde ya casi una de cada dos piezas procede de agencias.

Ese mayor protagonismo de las agencias, al margen de lo estrictamente cuantitativo, merece una mínima reflexión por los importantes cambios cualitativos que origina. En primer lugar, el trabajo audiovisual de las agencias compensa el efecto de disonancia y heterogeneidad causado por la utilización casi indiscriminada (según se ha documentado en el apartado anterior) de vídeos de producción ajena. Las agencias, en efecto, generan piezas de similar factura. Se acogen a los formatos clásicos: vídeos con locución (VTR), colas y totales.

Cuadro 9. Producción audiovisual procedente de agencias en los cinco cibermedios

\begin{tabular}{|c|c|c|c|c|c|}
\hline & abc.es & elconfidencial.com & elmundo.es & elpais.com & lavanguardia.com \\
\hline \multirow{2}{*}{2010} & 17 & 0 & 9 & 28 & 19 \\
& $(36,17 \%)$ & $(0 \%)$ & $(19,57 \%)$ & $(19,72 \%)$ & $(14,73 \%)$ \\
\hline \multirow{2}{*}{2014} & 55 & 9 & 21 & 58 & 46 \\
& $(35,26 \%)$ & $(12,33 \%)$ & $(26,58 \%)$ & $(46,77 \%)$ & $(24,73 \%)$ \\
\hline
\end{tabular}

Fuente: Elaboración propia

La duración de las piezas mantiene una considerable estabilidad. No suelen sobrepasar los dos minutos. La mayoría se mantiene entre el minuto y el minuto y medio. Los vídeos que no llegan al minuto son poco frecuentes, aunque no excepcionales. Incluso se localizan noticias que ni siquiera alcanzan los 40 segundos. El 24 de marzo elpais.com difunde un 
VTR de 23 segundos, con voz en off y elaborado por la agencias Atlas, sobre las elecciones en Francia. El 28 de marzo elmundo.es y elconfidencial.com recogen en sus portadas un VTR de 37 segundos sobre los problemas de inmigración irregular en Melilla. Sobre este mismo asunto elmundo.es había publicado el 18 de marzo un vídeo de 32 segundos con un solo plano, sin locución ni edición alguna. En este caso el material audiovisual no había pasado por el filtro de una agencia de noticias. Las diferencias formales y estructurales, aun con duraciones de piezas muy similares, saltan a la vista.

Además de formato y duración estable, estos vídeos de agencia presentan otros rasgos comunes. Suelen apoyarse en un texto leído y grabado (la clásica voz en off). Prefieren conformar una estructura de pirámide invertida (Oliva y Sitjà, 1992: 147; Cebrián Herreros, 1998: 201) o, aún más frecuentemente, de "pirámide diseminada" (Pérez, 2003: 105-117; Mayoral, 2008: 119). Tienden a emplear al menos dos o tres totales por pieza. Y no es extraño el uso de los totales de ambiente. Los rasgos citados en los párrafos anteriores acercan la producción audiovisual de las agencias de noticias al modelo de los informativos de televisión. Los recursos narrativos, los formatos, la duración de la piezas, el estilo del lenguaje verbal, la sintaxis audiovisual, la entonación en la lectura, el esfuerzo de edición, la coordinación de los diferentes códigos... Todo ello se asemeja al prototipo de noticia que un espectador puede ver en cualquier cadena de televisión de carácter generalista.

El modelo de las agencias que aquí se ha esbozado remite además a la versión clásica (pirámide invertida o diseminada, texto leído y grabado, vídeo de poco más de un minuto, etc.) de los informativos televisuales. Se citaron en el apartado anterior varios "semibrutos" que resultaban atípicos: entre ellos, la muerte de una niña en Treviño (abc.es, 19/03/2014) y muerte del alcalde de Bilbao, Iñaki Azkuna (elmundo.es, 24/03/2014). En relación con aquellos trabajos, cabe ahora citar las versiones televisivas -realmente ajustadas al modelo informativo predominante en televisión- que también fueron elaboradas por agencias: elpais.com y elconfidencial.com difundieron un VTR de Atlas (con locución, cuatro totales, un minuto y 17 segundos) sobre la muerte de la niña en Treviño; elpais.com publicó un VTR de 42 segundos sobre la muerte de Iñaki Azkuna. Estas dos piezas, a diferencia de los "semibrutos" antes referidos, sí que siguieron las pautas narrativas y estilísticas habituales en las noticias de televisión.

Incluso en los géneros predominantes se mantiene esta conexión entre las agencias y la televisión clásica. En ambos casos la noticia goza de un protagonismo indiscutible. Hasta el punto de que, como ocurre en los noticiarios de televisión, también las agencias adoptan el reportaje más como técnica narrativa que como verdadero género, con todas sus consecuencias en cuanto a extensión y profundidad. Puede comprobarse tal estrategia, por citar un único caso, en un supuesto reportaje de la agencia Atlas ( $a b c . e s, 20$ de marzo) sobre el final de las Fallas en Valencia. La pieza recoge doce totales (nueve declaraciones de ciudadanos y otros tres totales de ambiente), no aborda una cuestión de indiscutible novedad, emplea un tono distendido y con marcas claras de un estilo narrativo personal. Es decir, se acerca a lo que se tiende a considerar un reportaje. Sin embargo, dura un minuto y 13 segundos, de modo que no cabe aquí profundizar ni investigar más de lo habitual en cualquier noticia. 
Este supuesto reportaje, como tantas otras veces en televisión, viene a ser una "pieza reportajeada”, un tono y un estilo más que un género propiamente dicho. Resulta curioso comprobar cómo las agencias tienden a trasladar a los cibermedios ciertos comportamientos típicos en la televisión. No es casualidad que en este caso se haya logrado relación de complementariedad perfecta -no de jerarquía- entre los códigos visual y textual (Barroso, 1992: 242; Prósper y López, 1998: 23-24; Mayoral, 2008: 184; Benaissa, 2012: 202-227). Quiere esto último decir que las imágenes y las palabras buscan completarse mutuamente, sin que ninguno de los dos códigos se imponga con claridad al otro. Justamente eso es lo que ha venido procurando la televisión durante los últimos decenios.

Para terminar, conviene señalar que la tarea de las agencias ha ejercido una influencia muy fácil de reconocer en la producción audiovisual de los cibermedios analizados. A este respecto no hay más que comparar las muestras de 2010 y 2014. Se aprecia de inmediato que las páginas web estudiadas han podido establecer un interesante reparto de papeles: las agencias tienden a ocuparse de la parcela informativa ligada a la actualidad inmediata, a las noticias que más previsiblemente tendrán cabida en cualquier medio de comunicación; mientras tanto, los vídeos que llevan la firma del periódico se orientan más hacia el reportaje, hacia la entrevista, hacia la opinión o, en general, hacia cuestiones en las que se busca la originalidad. Este reparto de tareas ha podido consolidar la tendencia natural de las agencias a buscar noticias (información nueva seleccionada conforme a criterios clásicos) y también a atender toda suerte de convocatorias (actos informativos, ruedas de prensa, etc.), puesto que se presupone que los cibermedios solo pisarán este terreno en casos muy concretos en los que tengan un interés especial.

\subsection{Búsqueda y experimentación en la producción propia}

En el trabajo de campo realizado en noviembre de 2010 se constató que el 66,49\% de los vídeos registrados procedía de agencias o de producción ajena. El cibermedio, en estos casos, se limita a difundir la pieza, pero no se molesta en editarla o retocarla. En consecuencia, un 33,51\% de la muestra pertenecía a la producción propia de los cinco medios analizados. Tres años más tarde, la producción propia había descendido ligeramente: se situaba en el 31,23\% de los vídeos registrados. El Cuadro 7 ya mostró que la caída de los vídeos elaborados por los ocho cibermedios se debe interpretar, en realidad, del siguiente modo: aumenta la producción propia en términos absolutos (pues se pasa de 130 vídeos en 2010 a 193 en 2014), pero decrece en términos relativos por un incremento sustancial (de 258 a 425 piezas) en la producción ajena, fundamentalmente porque se dispara el número de trabajos audiovisuales procedentes de agencias (de 73 a 189).

El Cuadro 10 permite ver que esa subida de la producción propia se refleja en cuatro de los cinco cibermedios considerados. La excepción es lavanguardia.com, que contaba en 2010 con una producción propia inusualmente alta (64,34\%). Muy lejos de lo constatado en 2014: tan solo un 34,41\%. Tanto elmundo.es como elpais.com, con menos vídeos de producción propia publicados en portada, obtienen porcentajes más altos (53,16\% y 37,10\%, respectivamente, en 2014$)$, ya que sus pro- 
ducciones audiovisuales totales son menores. A cierta distancia se sitúa abc.es, donde ocurre algo similar a lo sucedido en lavanguardia.com: publica más vídeos de producción propia (pasa de 14 a 32), pero en relación con la producción total de 2010 y 2014 obtiene un tanto por ciento menor (29,79\% en 2010 y 20,51\% en 2014) para la producción propia.

Cuadro 10. Producción audiovisual propia en los cibermedios estudiados

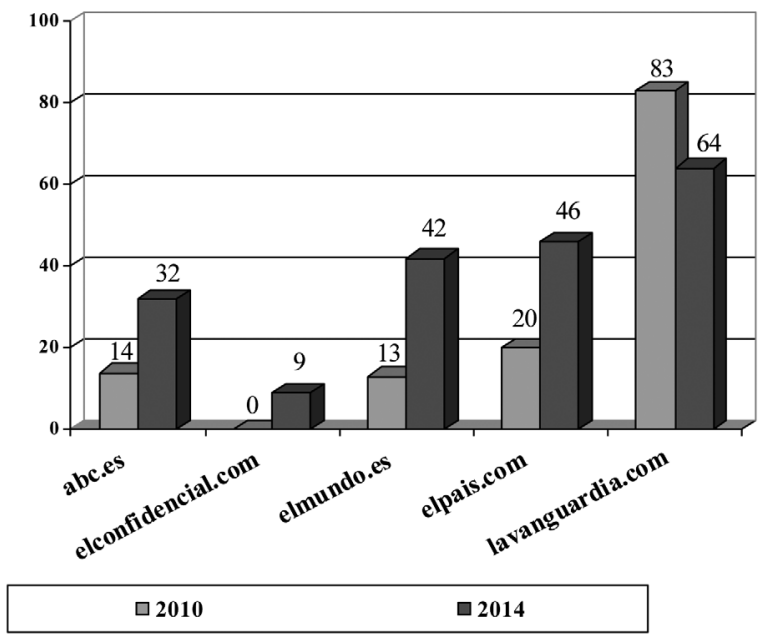

Fuente: Elaboración propia

Esta simple lectura obliga ya matizar y relativizar la sensación que pueden transmitir los datos de un análisis cuantitativo en estado puro. No es cierto -no es, al menos, del todo cierto- que la producción propia haya perdido protagonismo. En realidad lo que ha sucedido es que se ha disparado el número de piezas elaboradas por las agencias de noticias. Además, desde un punto de vista cualitativo, la producción propia resulta particularmente atractiva y sugerente. Porque si en las agencias aflora un modelo de información audiovisual muy cercano al de la televisión clásica, aquí se observa justo la tendencia contraria: la producción propia muestra síntomas inequívocos de búsqueda de nuevas fórmulas narrativas, de formatos diferentes, de estilos y procedimientos ajenos a la tradición periodística de la televisión.

En todos los medios analizados se constata ese esfuerzo de innovación y de experimentación que no se atisba, salvo excepciones, en los vídeos de agencias ni en la producción ajena. De todos modos, conviene advertir que este afán por innovar y experimentar cobra sentido precisamente gracias al modelo de los informativos de la televisión generalista. Tal es el punto de partida, la principal referencia. A partir de ese patrón narrativo y estilístico se buscan nuevas ideas.

Prueba de ello es que abundan en los cibermedios estudiados las piezas que reproducen, no ya los formatos habituales en televisión, sino incluso el propio concepto de programa de televisión. Cabe citar el caso de la lavanguardia.com. Allí se en-

48 | n 19, pp. 31-56 | doxa.comunicación 
contrarán programas de gastronomía, de viajes, de economía, de música o de información en medios online. Es habitual en estos programas, como sucede en televisión, que se recurra a un presentador para canalizar el relato. Se reproducen asimismo algunas pautas de la narrativa televisual. Es muy frecuente, por ejemplo, el uso de una pantalla -real o virtualdetrás del presentador. O la combinación de colas, VTR y totales durante el desarrollo del vídeo-programa. La duración de estas piezas es menor que en televisión. Oscila entre los cinco y los diez minutos. En alguna ocasión (la serie sobre prensa rosa en abc.es o el "aquí te pillo aquí te grabo" de elmundo.es, verbigracia) el falso directo no llega a los cinco minutos. La misma fórmula, con falso directo inicial, se utiliza a veces para introducir algún videoclip o alguna grabación musical realizada por el propio medio (en "Acustik", de lavanguardia.com, por ejemplo).

En relación con estos programas audiovisuales de los cibermedios, se advierte una tendencia al aprovechamiento de materiales ya difundidos. Esto ocurre, por ejemplo, en elmundo.es con el programa "LaSemana.zip" o en "infoweb", de lavanguardia.com. Entre los trabajos de campo de 2010 y 2014 se observa una clara expansión temática. De hecho, el último medio citado concibe el conjunto de su producción audiovisual como un canal de televisión que se denomina "La Vanguardia-TV”. Basta acceder a su programación ${ }^{13}$ para constatar la diversidad temática de los contenidos ofrecidos.

Cuadro 11. Entrevistas y reportajes en los cinco cibermedios

\begin{tabular}{|c|c|c|c|c|c|}
\hline & abc.es & elconfidencial.com & elmundo.es & elpais.com & lavanguardia.com \\
\hline \multirow{2}{*}{2010} & 3 & 2 & 9 & 15 & 33 \\
& $(6,38 \%)$ & $(8,33 \%)$ & $(19,57 \%)$ & $(10,56 \%)$ & $(25,58 \%)$ \\
\hline \multirow{2}{*}{2014} & 8 & 8 & 27 & 18 & 48 \\
& $(5,13 \%)$ & $(10,96 \%)$ & $(34,18 \%)$ & $(14,52 \%)$ & $(25,81 \%)$ \\
\hline
\end{tabular}

Fuente: Elaboración propia

En cuanto a los géneros, destaca el modo de composición de reportajes y entrevistas. El Cuadro 11 permite ver que lavanguardia.com, elmundo.es y elpais.com son los cibermedios que más atención prestan a estos dos géneros. Frente a la brevedad de ambos en los informativos de televisión, los medios digitales optan por piezas más extensas. Se encontrará excepcionalmente algún reportaje que supere los cinco minutos, pero la duración habitual oscila entre los tres y los cinco minutos. En las entrevistas no será tan extraño hallar piezas de mayor extensión. Elpais.com difunde el 26 de marzo de 2014 entrevista con Mario Vargas Llosa: en total, más de 23 minutos.

Parece claro que tiende a desaparecer el miedo a que los espectadores abandonen el vídeo por falta de interés en una materia concreta. Ese miedo ha influido decisivamente en el progresivo acortamiento de reportajes y entrevistas en las

13 Disponible en http://videos.lavanguardia.com/canal/destacados/index.html [consultado el 4 de mayo de 2014]. 
escaletas de los informativos televisuales (Pérez, 2003: 105-117). Porque si el tema o el personaje seleccionado no atrae a todo tipo de públicos, el informativo de televisión pierde audiencia. El espectador allí no tiene la posibilidad de pasar a la siguiente pieza. A lo sumo cambiará de canal. En los cibermedios, en cambio, el usuario sí puede pasar al siguiente texto o vídeo. Eso puede explicar que se publiquen reportajes tan poco convencionales como el que dedicó elmundo.es (31/03/2014) al proceso de elaboración de la lejía.

Lo lógico, además, es que solo pinchen el enlace del vídeo aquellos lectores que sientan cierto interés por un determinado tema o personaje. De ahí que la extensión de estas piezas sea mayor. Y de ahí también que el periodista (reportero o entrevistador) arriesgue con procedimientos narrativos más originales ${ }^{14}$. En lugar de estructuras de interés decreciente o pirámide invertida, la producción propia prefiere fórmulas discursivas o narrativas. En los reportajes se tiende a suprimir la típica voz en off habitual en las noticias. Con totales y planos de recurso basta para componer una narración atractiva. Esta práctica se traduce en un acercamiento (o hibridación) entre los géneros del reportaje y la entrevista.

Las dosis de creatividad son incluso mayores en géneros donde la subjetividad del periodista se valora especialmente. Tal es el caso de la crítica de cine. Si el VTR típico de un noticiario de televisión rara vez supera los dos minutos, aquí (en lavanguardia.com, particularmente) se encuentran fácilmente piezas de cinco minutos. En lugar de ir informando de las diferentes películas que llegan a la cartelera (como suele hacerse en televisión), el crítico de lavanguardia.com establece con rotundidad juicios de valor, y marca además un diálogo audiovisual entre las distintas películas que va enjuiciando. El resultado, en suma, es un producto audiovisual lleno de creatividad que combina información y opinión. Mucho más previsible es la fórmula de otros medios como elpais.com o abc.es, que recurren a una simple entrevista al crítico de referencia en el medio impreso. La imagen y el sonido de la entrevista se combinan con recursos de las películas que se van citando.

En el ámbito de la opinión es donde se aprecia con más nitidez que los cibermedios comienzan a desarrollar una narrativa audiovisual con personalidad propia. Parece haberse consolidado el "videoblog" (habitual en elmundo.es, elpais.com o abc.es). Estas piezas se acogen al modelo de falso directo ya conocido en televisión, aunque con una estructura habitualmente argumentativa. El predominio del texto sobre la imagen resulta casi absoluto. En general, estos videoblogs se limitan a ofrecer un discurso. El espectador se enfrenta a un orador que mira a la cámara y habla. Así pues, la complejidad audiovisual de estas piezas es mínima. Más novedosas y originales, aunque esporádicas, son propuestas discursivas como el "videodebate" (elpais.com publicó el 30 de marzo uno de casi nueve minutos).

La participación de los lectores, esencial en los nuevos medios, también ha encontrado un hueco en los vídeos. En lavanguardia.com se publica regularmente un VTR que incluye preguntas y sugerencias de ciudadanos. El producto final, que

14 Un solo ejemplo de esa creatividad: elmundo.es publica el 29 de marzo de 2014 una pseudoentrevista (algo más de seis minutos) a la modelo Nieves Álvarez. Se trata en realidad de una dramatización, porque la entrevistada finge conceder una entrevista (al tiempo que la concede), pero representa el papel de una actriz que se comporta como una diva. 
supera los 30 minutos, constituye una especie de chat que permite al cibermedio establecer un diálogo con los espectadores. En realidad se trata de otro vídeo-programa (también con presentador) llamado "Chat TV" que se une a la lista de programas ya comentados. Dentro de los géneros de opinión sorprenden otros dos programas de este mismo medio ("Poca broma" y "Focusings") por su estilo atrevido y desenfadado, con frecuencia casi cáustico.

Curioso y original es, por último, el trabajo de columnismo gráfico que publica de forma regular Krahnitos en lavanguardia.com. Estos vídeos suelen durar un minuto y medio. Incluyen música y dibujos. La serie animada no necesita rótulos ni locución para contar una pequeña historia que, por lo general, requiere de una interpretación simbólica o metafórica. En cierto modo se trasladan al vídeo las viñetas o las columnas gráficas que han publicado tradicionalmente los periódicos de papel. Otra aportación más de un cibermedio a los géneros y formatos conocidos por todos gracias a la televisión.

\section{Conclusiones}

El vídeo gana protagonismo en los cinco medios analizados. Este estudio ha confirmado la tendencia apuntada en otros trabajos (Greer y Mensing, 2006; Micó y Masip, 2008; Marrero, 2008; Masip y Micó, 2010; Guallar, Rovira y Ruiz, 2010; Masip, Micó y Meso, 2012; Cassany y otros, 2013): la producción audiovisual de los cibermedios crece. De las 388 piezas localizadas en el primer trabajo de campo se pasa a 618 en la segunda muestra, lo cual supone un incremento de un 59,28\% entre noviembre de 2010 y marzo de 2014. También se confirma lo señalado en algunos trabajos previos (Micó y Masip, 2008; Masip, 2010; Masip, Micó y Ayerdi, 2011) respecto al origen y a la autoría de los vídeos: existe un lento avance de la producción propia, que no acaba de consolidarse, pues ni siquiera alcanza a suponer un tercio de la producción audiovisual de los cinco medios analizados.

Al margen de lo estrictamente cuantitativo, esta investigación ha confirmado la hipótesis de la que partía. Los vídeos de los cinco cibermedios estudiados constituyen un conjunto multiforme, heterogéneo, en el que se advierten los rasgos característicos de modelos audiovisuales muy diversos. Dentro de la producción ajena se han identificado cuatro tipos de vídeos: piezas con edición completa, fragmentos de grabaciones (o de programas), resúmenes de brutos o "semibrutos" y, por último, vídeos de agencias.

La primera categoría suele reflejar acuerdos de colaboración entre empresas. Generalmente los cibermedios difunden vídeos confeccionados por cadenas de televisión del grupo al que pertenecen (elpais.com y Canal Plus, por ejemplo) o con los que mantienen acuerdos de colaboración (Gol TV y elmundo.es). Para los fragmentos de grabaciones y programas resulta de vital importancia el canal de vídeos YouTube, que alimenta con sus materiales a casi todos los medios analizados. En estos dos casos - piezas ya editadas y fragmentos- se valora especialmente que la plantilla del cibermedio casi no necesita de invertir tiempo alguno. Se trata de tomar un archivo y colgarlo de la web propia. En general se buscan situaciones 
llamativas, escenas sorprendentes, personajes famosos. Algunos autores (Díaz Arias, 2009: 68; Masip, 2010: 183) han advertido ya que esta producción audiovisual ajena constituye una fuente casi inagotable de curiosidades y vídeos anecdóticos.

Los llamados "semibrutos" (resúmenes de una grabación, sin apenas trabajo de montaje) demuestran que los medios online no han establecido aún un mínimo de calidad que permita decidir qué piezas audiovisuales deben ser difundidas y cuáles no. En este estudio se han documentado toda clase de situaciones: desde vídeos de veinte segundos (precedidos por otros veinte de publicidad) con un solo plano que muestran situaciones cotidianas sin trascendencia informativa hasta piezas de cinco minutos, sin locución ni estructura narrativa, que reproducen el típico premontaje sobre el que un periodista suele comenzar su tarea. Es previsible que los cibermedios adopten en el futuro criterios de calidad más exigentes que acaben por reducir-y en última instancia eliminar- la difusión de estos "semibrutos".

Este trabajo pretendía también confirmar o desmentir si los cinco medios seleccionados alternan propuestas piezas alejadas del informativo televisual (como las anteriores) con otras de nítido perfil periodístico. Los dos trabajos de campo han mostrado que también en esto los cibermedios se decantan por la hibridación. Todavía dentro de la producción ajena, junto a los tres tipos de piezas ya comentadas se han encontrado vídeos que replican el modelo clásico de los informativos de televisión. La producción audiovisual de las agencias de noticias goza de un protagonismo creciente. Desde el punto de vista cuantitativo, su presencia en las cinco páginas webs estudiadas se ha disparado: entre 2010 y 2014 el número de piezas de agencia ha aumentado un $158,9 \%$. Desde el punto de vista cualitativo, las agencias proporcionan homogeneidad, uniformidad, identidad. El resto de la producción ajena resulta miscelánea, dispar, estilísticamente imprevisible. Sin embargo, las agencias ofrecen un modo narrativo estable (VTR con locución y totales, por lo general con una estructura de pirámide invertida o diseminada). Además las agencias, al centrarse en la actualidad periodística más inmediata, permiten que la producción propia de los medios digitales se oriente a buscar contenidos originales y formas innovadoras.

Tal reparto de tareas explica que la producción propia haya logrado revitalizar géneros como el reportaje o la entrevista (cuya presencia en los noticiarios de televisión tiende a ser casi testimonial). Por las características del nuevo soporte, los cibermedios no temen que una entrevista o un reportaje sobrepasen los cinco minutos. Y, por lo descubierto en este trabajo, tampoco parecen temer que la narración periodística se aleje de los cauces ortodoxos y habituales en las noticias (locución, estructuras jerárquicas más que discursivas, etcétera). En este campo se busca, se experimenta, se innova. Fruto de ello son los hallazgos y las interesantes aportaciones -particularmente en los géneros de opinión- que se han citado en este estudio: la crítica cinematográfica (tan distinta de la habitual en los informativos de televisión), el videoblog, el videochat, el videodebate o la columna gráfica en vídeo de animación.

Como complemento de las hipótesis principales, esta investigación se propuso investigar hasta qué punto se está consolidando en los cibermedios una narrativa audiovisual propia, alejada de los moldes televisivos. La respuesta a esa cuestión 
se ha encontrado precisamente en la producción propia de los medios analizados. Y muy especialmente en aquellos cibermedios -lavanguardia.com, en especial- que han organizado su oferta audiovisual como si de un canal de televisión se tratara. Es claro que algunos medios online han dado ya el paso para construir esa nueva narrativa, ese nuevo modo de contar la realidad (e interpretar y opinar a partir de ella) con imágenes y sonidos. La mejor muestra de ello son los programas audiovisuales que se han documentado en este estudio, sobre todo en el trabajo de campo de 2014. No obstante, no es menos cierto que esa tendencia todavía es minoritaria y carece aún de una personalidad completamente definida.

\section{Referencias bibliográficas}

Aquino, R. et. al. (2002): The European Multi Media News Landscape Report. Heerlen: International Institute of Infonomics. Barroso, J. (1992): Proceso de la información de actualidad en televisión. Madrid: Instituto Oficial de Radio y Televisión.

Benaissa, S. (2012): “La comprensión y retención del mensaje informativo por la audiencia de televisión”, Icono 14, vol. 10, n. 3, pp. 202-227.

Berry, D. L. (1999): Comprehension and recall of internet news: a quantitative study of web page design. Paper presented at Annual Meeting of the Association for Education in Journalism and Mass Communication [http://eric.ed.gov/ ?id=ED434373, consultado el 16 de octubre de 2013].

Bock, M. A. (2012): Video Journalism: Beyond the One-Man Band. Nueva York: Peter Lang.

Boczkowski, P. J. (2004): Digitizing the News. Innovation in Online newspapers. Massachusetts: The MIT Press.

Bradshaw, P. y Rohumaa, L. (2011): The Online Journalism Handbook. Londres: Pearson Education Limited.

Canavilhas, J. (2007): Webnoticias. Propuesta de modelo periodístico para la www. Covilha: Livros Labcom.

Canet, F. y Prósper, C. (2009): Narrativa audiovisual: estrategias y recursos. Madrid: Editorial Síntesis.

Cassany, R. et. al. (2013): “El periodismo audiovisual en internet: funciones diferentes, vídeos diferentes”, Quaders del CAC, vol. 39, n. 16, pp. 37-51.

Cebrián Herreros, M. (1998): Información televisiva. Mediaciones, contenidos, expresión y programación. Madrid: Editorial Síntesis.

Cottle, S. y Ashton, M. (1999): "From BBC newsroom to BBC newscentre: on changing technology and journalist practices", Convergence: The journal of research into new media, vol. 5, n. 3, pp. 22-43.

Deuze, M. (2001): “Online Journalism: Modelling the First Generation of News Media on the World Wide Web”, First Monday, n. 10 [http://firstmonday.org/article/view/893/802\#author, consultado el 14 de diciembre de 2012]. 
Deuze, M. (2003): “The web and its journalisms: considering the consequences of different types of newsmedia online", New media \& society, vol. 5, n. 2, pp. 203-230 [http://www.multidesign.org/lib/Mark\%2BDeuze\%2B-\%2BThe\%2Bweb \%2Band\%2Bits\%2Bjournalisms.pdf, consultado el 28 de diciembre de 2012].

Deuze, M. (2004): “What is Multimedia Journalism?”, Journalism Studies, vol. 5, n. 2, pp. 139-152.

Díaz Noci, J. (2001): La escritura digital: hipertexto y construcción del discurso informativo en el periodismo electrónico. Bilbao: Servicio Editorial de la Universidad del País Vasco.

Díaz Noci, J. y Meso, K. (1999): Periodismo en Internet: modelos de la prensa digital. Bilbao: Servicio Editorial de la Universidad del País Vasco.

Edo, C. (2002): Del papel a la pantalla. La prensa en internet. Sevilla: Comunicación Social.

Edo, C. y Mayoral, J. (2011): "El incipiente desarrollo del ciberperiodismo audiovisual. Análisis de ocho cibermedios españoles”, La transformación del espacio mediático: Actas del III Congreso Internacional de Ciberperiodismo y Web 2.0. Bilbao: Universidad del País Vasco.

Erdal, I. J. (2009): “Repurposing of content in multi-platform news production”, Journalism Practice, vol. 3, n. 2, pp. 178-195.

García Jiménez, J. (1993): Narrativa audiovisual. Madrid: Cátedra.

Gordillo, I. (1999): Narrativa y televisión. Sevilla: Editorial MAD.

Greer, J. y Mensing, D. (2006): “The evolution of online newspapers: a longitudinal content analysis, 1997-2003”, en Xigen Li (ed.): Internet newspapers: the making of a mainstream medium. New Jersey: Lawrence Erlbaum Associates, pp. 13-32.

Guallar, J. (2008): “Prensa digital en 2007”, Anuario ThinkEPI, vol. 2, pp. 102-108.

Guallar, J.; Rovira, C.; Ruiz, S. (2010): "Multimedialidad en la prensa digital. Elementos multimedia y sistemas de recuperación en los principales diarios digitales españoles", El profesional de la información, vol. 19, n. 6, pp. 620-629.

Lancaster, K. (2012): Videojournalism on the web. Nueva York: Routledge.

López, X. (2008): "La eclosión del vídeo como mecanismo de comunicación política en Internet", en el Congreso Internacional Fundacional AE-IC, Santiago de Compostela.

Manovich, L. (2005): El lenguaje de los nuevos medios de comunicación. La imagen en la era digital. Barcelona: Paidós.

Marrero, L. (2008): "El reportaje multimedia como género del periodismo digital actual. Acercamiento a sus rasgos formales y de contenido", Revista Latina de Comunicación Social, n. 63, pp. 348-367 [http://www.revistalatinacs.org/ 08/29_40_Cuba/Liliam_Marrero.html, consultado el 7 de febrero de 2013].

Marshall, S. (2012): “BreakingNews launches TV ticker app”, Journalism.co.uk [http://www.journalism.co.uk/news/breakingnews-samsung-tv-ticker-app/s2/a548825/, consultado el 17 de octubre de 2013]. 
Mas Manchón, Ll. (2011): “Estructura del discurso televisivo: hacia una teoría de los géneros”, Cuadernos de Información, vol. 29, pp. 78-90.

Masip, P. (2010): “El video en los cibermedios: algunas certezas y muchas dudas”, Anuario ThinkEPI, n. 4, pp. 180-185. [http://www.thinkepi.net/el-video-en-los-cibermedios-algunas-certezas-y-muchas-dudas, consultado el 18 de abril de 2013].

Masip, P. et. al. (2010): “Investigación internacional sobre ciberperiodismo: hipertexto, interactividad, multimedia y convergencia”, El profesional de la información, vol. 19, n. 6, pp. 568-576. [DOI: http://hdl.handle.net/10171/13561, consultado el 13 junio de 2013].

Masip, P.; Micó, J. Ll; Meso, K. (2012): “Periodismo multimedia en España. Análisis de los contenidos multimedia en la prensa digital. III Congreso Internacional de la Asociación Española de Investigación de la Comunicación “Comunicación y riesgo" [http://www.aeic2012tarragona.org/comunicacions_cd/ok/100.pdf, consultado el 23 de septiembre de 2013].

Mayoral, J. et. al. (2008): Redacción periodística en televisión. Madrid: Editorial Síntesis.

Micó, J. Ll. y Masip, P. (2008): “Recursos multimedia en los cibermedios españoles”, Trípodos, vol. 23, pp. 89-105.

Micó, J. Ll.; Masip, P.; Barbosa, S. (2009): "Models of business convergence in the information industry: A mapping of cases in Brazil and Spain”, Brazilian journalism research, vol. 5, pp. 123-140.

Murray, J. (1999): Hamlet en la holocubierta. El futuro de la narrativa en el ciberespacio. Barcelona: Paidós.

Negredo, S. (2011): “The Growing Impact of Video in Online News Genres”, comunicación en "Diversity of Journalisms. Proceedings of ECREA/CICOM Conference", Pamplona, 4-5 de julio.

Negredo, S. (2013): El video de producción original en cibermedios. Tesis doctoral leída en la Facultad de Comunicación de la Universidad de Navarra.

Neuberger, Ch. et. al. (1998): “Online. The future of newspapers? Germany's dailies on the world wide web”, Journal of computer mediated communication, 1998, vol. 4, n. 1.

Nielsen, J. (1999): Designing Web Usability: The practice of simplicity. Indianápolis: New Riders Publishing.

Oliva, Ll. y Sitjà, X. (1992): Las noticias en televisión. Madrid: Instituto Oficial de Radio y Televisión.

Pérez, G. (2003): Curso básico de periodismo audiovisual. Pamplona: Eunsa.

Peer, L. y Ksiazek, Th. B. (2011): “YouTube and the challenge to Journalism. New standards for news videos online”, Journalism Studies, vol. 12, n. 1, pp. 45-63.

Picard, R. (2013): “News organizations or Journalism: Which should concern us?”, conferencia impartida en el I Simposio "La supervivencia del periodismo en la era post digital", celebrado en Madrid. 
Prósper, J. y López, C. (2001): Elaboración de noticias y reportajes audiovisuales. Valencia: Fundación Universitaria San Pablo CEU.

Russial, J. (2009): “Growth of multimedia not extensive at newspapers”, Newspaper research journal, vol. 30, n. 3, pp. 58-74.

Salaverría, R. (2005): Redacción periodística en internet. Pamplona: Eunsa.

Selinger, V. C. (2008): Escribir un guión de cine o televisión. Barcelona: El Andén.

Sundar, S. Sh. (2000): "Multimedia effects on processing and perception of online news: a study of picture, audio and video downloads", Journalism and mass communication quarterly, vol. 77, n. 3, pp. 480-499.

Shultz, T. (1999): "Interactive options in online journalism: a content analysis of 100 US newspapers", Journal of computer mediated communication, vol. 5, n. 1.

Thurman, N. y Lupton, B. (2009): “Convergence calls: Multimedia storytelling at British news websites”, Convergence: the international journal of research into new media technologies, vol. 14, n. 4, pp. 439-455.

Vale, E. (1996): Técnicas del guión para cine y televisión. Barcelona: Gedisa.

Williams, A. y Franklin, B. (2007): Turning around the tanker: implementing Trinity Mirror's online strategy. Cardiff: Cardiff University.

Zamarra López, M. (2010): “El uso del audio y del vídeo en los ciberperiódicos”, en Cebrián Herreros, Manuel (ed.): Desarrollos del periodismo en internet. Zamora: Comunicación Social, pp. 65-79. 